\title{
Microbial Transformation of Lucanthone by Growing Cultures, Washed Mycelia and Non-germinating Spores of Fungi from the Aspergillus Group
}

\author{
By HAMDALLAH H. ZEDAN, * OSSAMA M. EL-TAYEB AND \\ MAHMOUD N. WALASH $†$ \\ Faculty of Pharmacy, Cairo University, Cairo, Egypt
}

(Received 21 April 1982; revised 5 August 1982)

\begin{abstract}
Whole broth cultures, washed mycelia and non-germinating spores of 13 aspergilli scored from among 91 moulds isolated from soil and air transformed lucanthone (I) into three to five products with increased polarity. Biotransformations brought about by actively growing cultures were also performed by washed mycelia and non-germinating spores of the same strains. Lucanthone (I) was oxidized by growing cultures, washed mycelia and spore suspensions of an Aspergillus species (no. 2) into: hycanthone (II) as the main product, its aldehyde analogue (III) and its carboxylic acid derivative (IV). The pathway of lucanthone (I) oxidation by this strain involved hydroxylation of the 4-methyl group (to give hycanthone, II) followed by dehydrogenation of the resulting primary alcohol (to give the aldehyde, III). The aldehyde III was finally slowly oxidized to the corresponding carboxylic acid analogue IV. Evidence is presented to show that mycelial and spore enzymes effecting these oxidative reactions are intracellular and non-inducible in nature. Spore-mediated transformations were found not to require a source of energy and could be conducted in distilled water over a wide range of incubation temperature (from 4 to $37^{\circ} \mathrm{C}$ ). Use of the spores in successive transformations did not affect lucanthone (I) hydroxylation into hycanthone (II) or the dehydrogenation of the latter into the aldehyde analogue (III) but the ability of the spores to oxidize the aldehyde (III) to the carboxylic acid (IV) was lost.
\end{abstract}

\section{INTRODUCTION}

Interest in schistosomiasis led to the introduction of 1-[(2-diethylaminoethyl)-amino]-4methylthioxanthen-9-one (lucanthone, I) as the first oral, non-antimonial schistosomicidal drug (Kikuth \& Könnert, 1948). However poor human tolerance militated against its being the drug of choice (Blair, 1958). Biochemical and metabolic studies on lucanthone (I) indicated that the drug is being converted in vivo to the active metabolite 1-[(2-diethylaminoethyl)-amino]-4hydroxymethylthioxanthen-9-one (hycanthone, II) since lucanthone was inactive in vitro (Rosi et al., 1965, 1967). Hycanthone (II) is a highly active schistosomicidal agent when given orally or intraperitoneally (Rosi et al., 1967) and has also been found to be effective against Trichinella spiralis (Gawish, 1974).

The microbial conversion of lucanthone (I) to hycanthone (II) by growing whole cultures of a strain of Aspergillus sclerotiorum has been reported previously (Rosi et al., 1967). However, the microbiological transformation of this substrate by non-germinating spores is interesting from several points of view. The non-germinating spores of fungi and actinomycetes, generally regarded as a metabolically dormant stage in the life cycle of these micro-organisms, are portentially capable of effecting a wide range of conversions on many organic molecules including steroids, fatty acids, triglycerides, carbohydrates, antibiotics and flavenoids (Vézina et al., 1968; Vézina \& Singh, 1975). As these molecules were found to be susceptible to spore enzymes, there is no reason to believe that other organic substrates will not be transformed by

$\dagger$ Present address: Chemical Industries Development Co. (C.I.D.), Cairo, Egypt. 
<smiles></smiles>

Fig. 1. Possible mechanism for the metabolism of lucanthone (I) by the spores and the mycelium of Aspergillus sp. (no. 2).

non-germinating spores. The nature of metabolites that might be obtained in spore-mediated lucanthone transformations may shed light on the metabolic pathway of lucanthone (I) by nongerminating spores which could parallel its metabolism in man. The present work reports on the biotransformation of lucanthone (I) by non-germinating spores, washed mycelia and actively growing cultures of some moulds belonging to the Aspergillus group.

\section{METHODS}

Micro-organisms. A total of 91 moulds isolated from Egyptian soil and air were screened for their ability to transform lucanthone (I). Aspergillus sclerotiorum known to convert lucanthone (I) to hycanthone (II), its aldehyde (III) and carboxylic acid (IV) analogues (Rosi et al., 1967) was kindly provided by the Centraalbureau voor Schimmelcultures, Javalaan 20, Baarn, The Netherlands. All cultures were maintained on slants of Malt Extract Agar (Difco), stored at $4{ }^{\circ} \mathrm{C}$ and subcultured monthly.

Chemicals. Lucanthone (I) hydrochloride was a product of Burroughs Wellcome. Hycanthone (II), 1-(2diethylaminoethyl)-aminothioxanthen-9-one-4-carboxaldehyde (III) and 1-(2-diethylaminoethyl)-aminothioxanthen-9-one-4-carboxylic acid (IV) were prepared by incubation of lucanthone (I) with $A$. sclerotiorum (Rosi et al., 1967). The chemical structures of these compounds are presented in Fig. 1. Silica gel $\mathrm{G}$ was a product of Merck. Dimethylformamide (DMF) was obtained from BDH. Other chemicals were reagent grade; organic solvents were purified and twice distilled before use.

Production and standardization of non-germinating spores. Each of the isolated fungi was sporulated on Sabouraud's Dextrose Agar (Difco) in $200 \mathrm{ml}$ Roux bottles. The bottles were inoculated by a freshly prepared spore suspension of the isolate and incubated at $25-28^{\circ} \mathrm{C}$ till abundant sporulation was attained (5-8 d). Spores were harvested in sterile distilled water, filtered through sterile cheese cloth, washed several times by centrifugation, resuspended in distilled water, and stored at $4{ }^{\circ} \mathrm{C}$ for use. Portions of the spore suspensions were examined microscopically to ensure their freedom from mycelial debris, counted in a haemocytometer, and then diluted with distilled water to give $10^{8}$ spores per $\mathrm{ml}$. Variations from these standard conditions are indicated in the text.

Production and standardization of washed mycelia. Each organism was grown in a $250 \mathrm{ml}$ Erlenmeyer flask containing $50 \mathrm{ml}$ of Soyabean Meal Broth (BDH) for $72 \mathrm{~h}$ at $25-28^{\circ} \mathrm{C}$ on a reciprocating shaker $(200$ strokes $\mathrm{min}^{-1}$ ). Portions $(3 \mathrm{ml}$ ) of the resulting cellular suspension formed during this period were then used to inoculate a number of fresh flasks of the same medium. These flasks were incubated on a reciprocating shaker 200 strokes $\min ^{-1}$ for $24 \mathrm{~h}$ before the inducer (if any) was added and incubation was continued for $72 \mathrm{~h}$. At the end of the incubation period, the contents of replicate flasks were pooled and mycelium was collected by filtration through cheese cloth. The pooled cellular suspension was washed by shaking for $5 \mathrm{~min}$ in distilled water and mycelium was then separated by centrifugation and resuspended in distilled water. 
Measured portions of the resulting suspension were taken in duplicate, filtered, rinsed with water, dried for $24 \mathrm{~h}$ at $105^{\circ} \mathrm{C}$ and used for dry weight determination. The average weight of mycelium was calculated and the cells in the remaining part of the suspension were collected by centrifugation and resuspended in water to give a final concentration of $2.5 \mathrm{mg}$ (dry weight) per $\mathrm{ml}$. Variations from these standard conditions are indicated in the text.

Substrate transformations. (a) By whole broth cultures. Unless otherwise specified the transformation of lucanthone (I) by growing fungal mycelia was in Soyabean Meal Broth. A fresh stock culture of each isolate was used to inoculate $50 \mathrm{ml}$ of the sterile medium in a $250 \mathrm{ml}$ Erlenmeyer flask. The inoculated flasks were incubated at $25-28{ }^{\circ} \mathrm{C}$ on the shaker for $48 \mathrm{~h}$ and a $5 \%$ inoculum from the resulting growth was used to inoculate a fresh flask of the same medium which was further incubated for $48 \mathrm{~h}$. The substrate dissolved in DMF was then added to give a concentration of $0.5 \mathrm{mg} \mathrm{ml}^{-1}$ and the culture medium was incubated for $72 \mathrm{~h}$ on the shaker $\left(200\right.$ strokes min $\left.^{-1}\right)$.

(b) By spores. Transformations by non-germinating spores were carried out in $250 \mathrm{ml}$ Erlenmeyer flasks each containing $50 \mathrm{ml}$ of the spore suspension $\left(10^{8}\right.$ spores $\left.\mathrm{ml}^{-1}\right)$. The substrate dissolved in DMF was added to each flask to give a concentration of $0.5 \mathrm{mg}$ per $\mathrm{ml}$ suspension, $\mathrm{pH}$ was $5 \cdot 0$. The flasks were incubated on the shaker at $25-28^{\circ} \mathrm{C}$ for $72 \mathrm{~h}$.

(c) By washed mycelia. Transformations by washed mycelia were in $250 \mathrm{ml}$ Erlenmeyer flasks, each containing $50 \mathrm{ml}$ mycelial suspension $\left(2.5 \mathrm{mg}\right.$ dry weight $\left.\mathrm{ml}^{-1}\right)$. An appropriate volume of the substrate solution was added to each flask to give a concentration of $0.5 \mathrm{mg}$ substrate per $\mathrm{ml}$ of suspension. The flasks were incubated with shaking at $25-28^{\circ} \mathrm{C}$ for $72 \mathrm{~h}$. Variations from the above mentioned conditions are indicated in the text.

Analytical determinations. At the end of the incubation period, the contents of each flask were made alkaline (pH 8) with a few drops of concentrated solution of ammonia and extracted with chloroform. The chloroform extract was dried over anhydrous sodium sulphate, evaporated to dryness under vacuum and kept for analysis.

(1) TLC analysis. The course of substrate transformation was followed by TLC on Silica Gel G plates. Starting parallel spots, $2 \mathrm{~cm}$ away from each side of the plate and $2 \mathrm{~cm}$ apart, were made from the chloroform extracts as well as from solutions of reference substances. The spots were left to dry in air and the plates were developed in methanol/ammonia $(100: 1 \cdot 5, \mathrm{v} / \mathrm{v})$.

(2) Detection of the transformation products on chromatoplates. The spots of the transformation products and residual substrate were located on the plates visually as well as by spraying with $0.5 \%$ aqueous solution of potassium permanganate. The outline of each spot was marked by a sharp pin.

(3) Quantitative estimation of transformation products. A spot area method (Stahl, 1969) was used as a screening procedure for quantitative estimation of residual lucanthone (I) and its transformation products. Portions of lucanthone (I) solution containing from 50 to $200 \mu \mathrm{g}$ were spotted on Silica Gel $\mathrm{G}$ plates. The plates were developed following the procedure mentioned above. Each spot was then marked with a sharp pin and accurately traced on calico paper. A standard curve was then prepared by plotting the logarithms of the concentrations against their respective spot areas. The amount of each transformation product in a given extract was accordingly calculated as lucanthone (I) by reference to the standard curve after subjecting the extract to TLC. The results were expressed as percentages of substrate transformed.

In the course of lucanthone (I) transformation by different forms of the Aspergillus sp. (no. 2), conversion products were assayed quantitatively by UV spectroscopy. The spots of transformation products were eluted from developed plates with $0.05 \mathrm{M}$-sulphuric acid and their absorbances at $257 \mathrm{~nm}$ were taken as a measure of their concentrations by reference to standard curves.

Separation and identification of transformation products. Transformation products were separated from crude chloroform extracts by spotting each extract as a band on preparative Silica Gel G plates ( $0.5 \mathrm{~mm}$ thickness). The plates were developed as mentioned before where the transformation products as well as the residual substrate appeared as yellow bands. Each of these bands was scraped off, eluted with a suitable volume of absolute methanol, filtered over anhydrous sodium sulphate, dried under vacuum and recrystallized from methanol.

Transformation products were identified by reference to authentic samples. All melting points were determined on Koffler melting point apparatus. IR spectra were recorded from $\mathrm{KBr}$ discs on a Unicam SP-1000 spectrophotometer. UV absorption spectra were recorded in $0.05 \mathrm{M}$-sulphuric acid on a Beckman DB-GR recording spectrophotometer. NMR spectra were run on a Varian A-60 NMR spectrometer using trimethylsilane as the internal standard.

\section{RESULTS}

\section{Transformation of lucanthone (I) by various moulds}

Whole broth cultures, washed mycelia and non-germinating spores of a total of 91 moulds were screened for conversion of lucanthone (I). Control flasks of fresh medium only, nongerminating spore suspensions only, suspensions of washed mycelia only and suspensions of fresh medium to which the substrate was added were similarly incubated and analysed. These 
Table 1. Transformation of lucanthone by whole broth cultures of active fungi

$\begin{array}{ccccccc}\text { Isolate } & \begin{array}{c}\text { Residual } \\ \text { substrate } \\ \text { no. }\end{array} & \overbrace{\begin{array}{c}\text { Compound } \\ \text { (II) }\end{array}} & \begin{array}{c}\text { Compound } \\ \text { (III) }\end{array} & \begin{array}{c}\text { Compound } \\ \text { (IV) }\end{array} & \begin{array}{c}\text { Compound } \\ \text { (V) }\end{array} & \begin{array}{c}\text { Compound } \\ \text { (VI) }\end{array} \\ 1 & 43 & 32 & 13 & 12 & - & - \\ 2 & 25 & 35 & 21 & 18 & - & - \\ 3 & 27 & 37 & 22 & 14 & - & - \\ 4 & 23 & 30 & 7 & 6 & 15 & - \\ 5 & 21 & 34 & 17 & 17 & 10 & - \\ 6 & 43 & 32 & 15 & 10 & - & - \\ 7 & 26 & 25 & 9 & 9 & - & - \\ 8 & 49 & 29 & 14 & 8 & 25 & - \\ 9 & 27 & 31 & 9 & 8 & 21 & - \\ 10 & 33 & 33 & 6 & 9 & - & - \\ 11 & 23 & 34 & 10 & 11 & - & - \\ 12 & 39 & 43 & 5 & 14 & -\end{array}$

controls were used to exclude spots resulting from autodegradation (if any) of the substrate or from constituents of the fermentation medium, or both, or produced by the culture itself.

The results obtained for lucanthone (I) transformation by growing cultures, washed mycelia and non-germinating spores are presented in Table 1. Whole growing cultures of 13 of the 91 under test were able to convert lucanthone (I) to three to five transformation products including hycanthone (II) under these experimental conditions. No qualitative differences were observed in the bioconversion activity of whole broth cultures, washed mycelia or non-germinating spores of any single culture; all were active lucanthone (I) metabolizers and in all cases the same transformation products were obtained. Active cultures were given isolate numbers 1 to 13 and all these isolates were from the Aspergillus group.

Transformation of lucanthone (I) by the isolate no. 2 identified as an Aspergillus $s p$.

Under the screening conditions isolate no. 2 was one of the most active cultures; it transformed lucanthone into three products with increased polarity. This isolate was identified as an Aspergillus sp. and was thus selected for further study.

Transformation of lucanthone (I) by whole broth culture. Lucanthone (I) was converted by whole broth cultures of the Aspergillus isolate no. 2 into three transformation products (II, III and IV). The yields of these products ranged between 18.2 and $35.5 \%$ (Table 1). All products retained the yellow colour of the substrate. They were characterized as hycanthone (II), its aldehyde analogue (III) and its carboxylic acid derivative (IV), respectively; and their identity was established by direct comparison with samples prepared by the procedure of Rosi et al. (1967).

Transformation of lucanthone (I) by washed mycelium. Washed mycelia of the Aspergillus sp. no. 2 converted lucanthone (I) into products II, III and IV as in case of whole broth culture. No lag period was observed and the transformation products were detected in the medium within $1 \mathrm{~h}$ of incubation (Fig. 2). However, the relative proportions of these products varied with the period of incubation. As the substrate started to disappear, two transformation products (hycanthone, II and its aldehyde analogue, III), followed by a third one (the carboxylic acid derivative, IV) accumulated gradually. Maximum conversion was obtained within $20 \mathrm{~h}$ where hycanthone (II) was the main conversion product $(35.5 \%$ yield). The same course of transformation was observed when conversion was conducted in the presence of chloramphenicol or streptomycin $\left(100 \mu \mathrm{g} \mathrm{ml}^{-1}\right)$; both are antibiotics known to inhibit protein synthesis.

When the aldehyde (III) was incubated for $24 \mathrm{~h}$ with washed mycelia, the carboxylic acid analogue (IV) was the only conversion product that could be detected in small yields. However, the mycelia lost their transformation activities by autoclaving at $120^{\circ} \mathrm{C}$ for $10 \mathrm{~min}$ and clear supernatants separated from whole broth cultures failed to transform lucanthone (I) to any extent. 


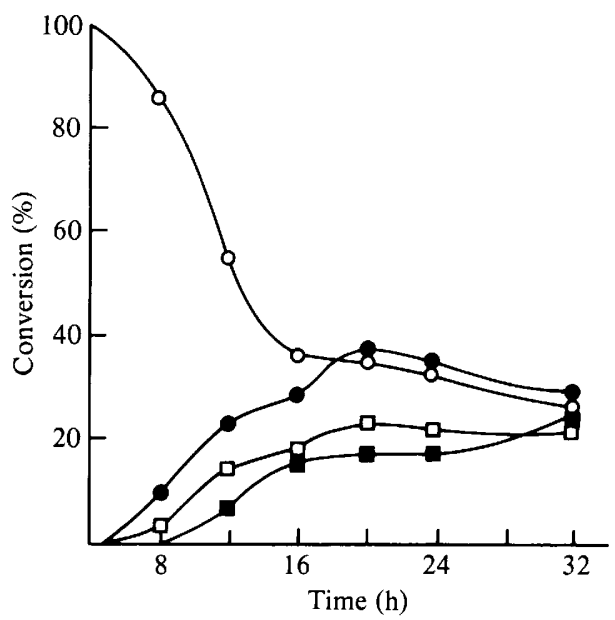

Fig. 2. Time course of the transformation of lucanthone, I (O) into hycanthone, II (O), the aldehyde analogue, III ( $\square$ ) and the carboxylic acid derivative, IV ( $\square$ ) by washed non-induced mycelia of the Aspergillus sp. (no. 2). Mycelia, $2.5 \mathrm{mg} \mathrm{dry} \mathrm{wt} \mathrm{ml}^{-1}$; substrate, $0.5 \mathrm{mg} \mathrm{ml}^{-1}$; incubation temperature, $25-28^{\circ} \mathrm{C}$.

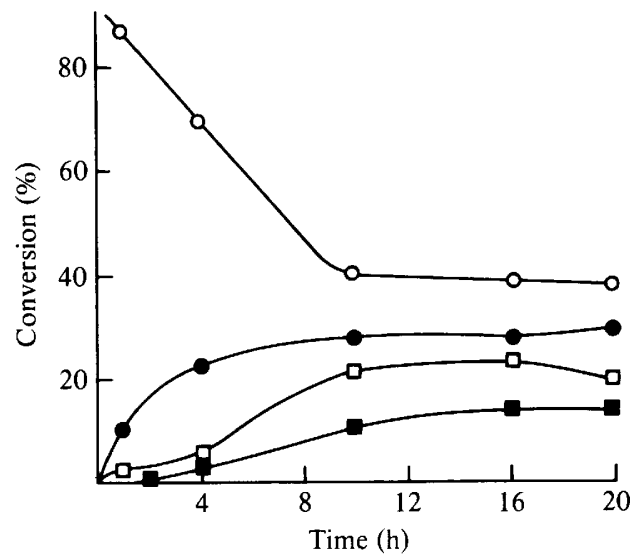

Fig. 3. Time course of the transformation of lucanthone, I $(O)$ into hycanthone, II (O), the aldehyde analogue, III ( $\square$ ) and the carboxylic acid derivative, IV ( $\square$ ) by washed non-induced spores of the Aspergillus sp. (no. 2). Spores, $10^{8} \mathrm{ml}^{-1}$; substrate, $0.5 \mathrm{mg} \mathrm{ml}^{-1}$; incubation temperature, $25-28^{\circ} \mathrm{C}$.

Transformation of lucanthone (I) by non-germinating spores. Washed non-germinating spores ( $10^{8}$ spores $\mathrm{ml}^{-1}$ ) of the Aspergillus sp. no. 2 transformed lucanthone (I) into hycanthone (II), its aldehyde (III) and its carboxylic acid (IV) analogues, as with whole broth cultures and washed mycelia. No lag period was observed and all transformation products were detected within $1 \mathrm{~h}$ of incubation. Figure 3 illustrates the course of lucanthone transformation by the spores. As the substrate disappeared gradually, hycanthone (II) and its aldehyde analogue (III) continued to accumulate in the medium, whereas the carboxylic acid analogue (IV) was formed in small concentrations. Maximum transformation was attained within $10 \mathrm{~h}$ of incubation where hycanthone (II) was the main product $(28 \%)$. The same course of transformation was observed when the process was carried out in the presence of chloramphenicol or streptomycin $(100 \mu \mathrm{g}$ $\mathrm{ml}^{-1}$ ). Also, hycanthone (II) was converted to the aldehyde (III) and the carboxylic acid (IV) analogues in 12 and $9 \%$ yields, respectively, after incubation with the spores for $24 \mathrm{~h}$. When the aldehyde (III) was incubated for $24 \mathrm{~h}$ with non-germinating spores of this Aspergillus sp., the carboxylic acid analogue (IV) was the only conversion product that could be detected in small yields. 


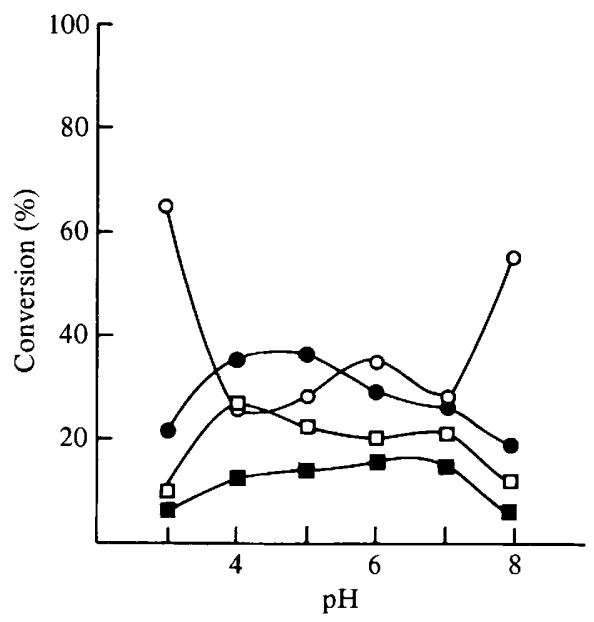

Fig. 4. Effect of $\mathrm{pH}$ of incubation on the conversion of lucanthone, I (O) into hycanthone, II (O), the aldehyde analogue, III ( $\square$ ) and the carboxylic acid derivative, IV ( $\square$ ) by spores of the Aspergillus sp. (no. 2). Spores, $2 \times 10^{8} \mathrm{ml}^{-1}$; substrate, $0.5 \mathrm{mg} \mathrm{ml}^{-1}$; incubation temperature, $25-28^{\circ} \mathrm{C}$; time, $24 \mathrm{~h}$.

Moreover, when the carboxylic acid (IV) was incubated with the non-germinating spores for $72 \mathrm{~h}$ no conversion products could be detected in the medium.

Factors affecting lucanthone transformation activity of non-germinating spores. (i) Effect of energy source. No significant qualitative or quantitative differences were observed when the transformation was carried out in the absence or the presence of $\left(0.5 \mathrm{mg} \mathrm{ml}^{-1}\right)$ dextrose, sucrose, lactose, maltose, mannitol or soluble starch in the spore suspension. In subsequent transformations, no energy source was included in the medium.

(ii) Effect of $\mathrm{pH}$. The effect of $\mathrm{pH}$ on the conversion of lucanthone (I) by the non-germinating spores is illustrated in Fig. 4. The substrate was incubated with spores suspended in phosphate buffers of various $\mathrm{pH}$ values for $24 \mathrm{~h}$. Maximum transformation and maximum yield of hycanthone (II) were observed when the transformation was carried out at a $\mathrm{pH}$ ranging between 4 and 5 . At lower or higher $\mathrm{pH}$ values, there was a gradual reduction in spore activity The substrate (I) did not undergo autodegradation at the selected $\mathrm{pH}$ values when control flasks containing the substrate only dissolved in phosphate buffers were incubated under the same conditions.

(iii) Effect of substrate concentration. Spore suspensions were incubated with various concentrations of lucanthone (I). As shown in Fig. 5, the conversion activity of the spores increased by increasing substrate concentration from 0.1 to $0.7 \mathrm{mg}$ per $\mathrm{ml}$. However, the relative proportions of hycanthone (II), the aldehyde analogue (III) and the carboxylic acid (IV) varied with substrate concentration. Maximum yields of hycanthone (II) were obtained at a substrate concentration of $0.7 \mathrm{mg} \mathrm{ml}^{-1}$. At higher substrate concentrations, there was increased reduction in spore activity and subsequently in yields of all products.

(iv) Effect of incubation temperature. The effect of incubation temperature on the transformation of lucanthone (I) by non-germinating spores is shown in Table 2 . Increased spore activity was noticed when the transformation was carried out at 37 or $25^{\circ} \mathrm{C}$ rather than at $4{ }^{\circ} \mathrm{C}$. However, although no significant difference could be observed in the yield of lucanthone (II) when the transformation was carried out at 4 or $25^{\circ} \mathrm{C}$, there was a twofold increase in the yield of compound III at $25^{\circ} \mathrm{C}$. At $37^{\circ} \mathrm{C}$, the yield of hycanthone was increased and that of compound III was decreased.

(v) Heat resistance of spore enzymes. Spores were tested for conversion of lucanthone (I) after heating at various temperatures for $1 \mathrm{~h}$. No significant qualitative differences in activity were noted when the transformation was carried out by spores heated at temperatures ranging from $40^{\circ} \mathrm{C}$ to $100^{\circ} \mathrm{C}$ and cooled to room temperature before the addition of the substrate (Table 3 ). 


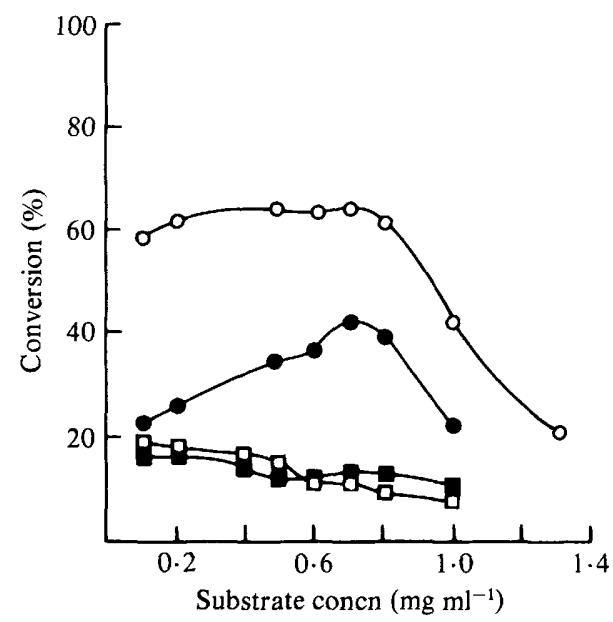

Fig. 5. Effect of lucanthone $(\mathrm{I})$ concentration $(\mathrm{O})$ on its conversion into hycanthone, II $(O)$, the aldehyde analogue, III ( $\square$ ) and the carboxylic acid derivative, IV ( $\square$ ) by spores of the Aspergillus sp. (no. 2). Spores, $2 \times 10^{8} \mathrm{ml}^{-1} ; \mathrm{pH}, 5$; incubation temperature, $25-28{ }^{\circ} \mathrm{C}$; time, $24 \mathrm{~h}$.

Table 2. Effect of incubation temperature on the transformation of lucanthone by non-germinating spores of Aspergillus sp. (no. 2)

Incubation
temperature $\left({ }^{\circ} \mathrm{C}\right)$

4
25

25
37

Percentage conversion tc:

$\begin{array}{ccc}\text { Hycanthone (II) } & \text { Compound (III) } & \text { Compound (IV) } \\ 28 & 10 & 6 \\ 25 & 22 & 7 \\ 31 & 13 & 8\end{array}$

Table 3. Effect of heat on the transformation of lucanthone by non-germinating spores of Aspergillus sp. (no. 2)

\author{
Heating \\ temperature
}

$40^{\circ} \mathrm{C}, 1 \mathrm{~h}$

$50^{\circ} \mathrm{C}, 1 \mathrm{~h}$

$70^{\circ} \mathrm{C}, 1 \mathrm{~h}$

$100^{\circ} \mathrm{C}, 1 \mathrm{~h}$

$121^{\circ} \mathrm{C}, 10 \mathrm{~min}$

\begin{tabular}{ccc}
\multicolumn{3}{c}{ Percentage conversion to: } \\
Hycanthone (II) & Compound (III) & Compound (IV) \\
29 & 21 & 16 \\
25 & 15 & 13 \\
23 & 17 & 10 \\
22 & 18 & 6 \\
- & - & -
\end{tabular}

However, this heat treatment led to a partial loss of spore activity. Complete loss of conversion activity was observed when the spores were autoclaved at $121^{\circ} \mathrm{C}$ for $10 \mathrm{~min}$.

(vi) Effect of spore concentration. Spore suspensions of the Aspergillus sp. (no. 2) ranging from $10^{8}$ to $10^{10}$ spores $\mathrm{ml}^{-1}$ were used to transform lucanthone by the usual procedure. The results obtained are presented in Table 4. The transformation activity was increased by increasing the spore concentration from $10^{8}$ to $4 \times 10^{8}$ spores $\mathrm{ml}^{-1}$ although the relative proportions of hycanthone (II) and other metabolites varied slightly with spore concentration. Maximum yields of hycanthone (II) and its aldehyde analogue (III) were obtained at a spore concentration of $2 \times 10^{8}-4 \times 10^{8}$ spores $\mathrm{ml}^{-1}$. Increasing the concentration of the spores to more than $4 \times$ $10^{8}$ spores $\mathrm{ml}^{-1}$ resulted in a lowered conversion activity.

(vii) Re-use of the spores in successive transformations. The stability of spore enzymes was examined by using the same spore suspension in successive transformations. After each process, the spores were separated by centrifugation, washed once with water, resuspended in an equal 
Table 4. Effect of spore concentration on the transformation of lucanthone by non-germinating spores of Aspergillus sp. (no. 2)

\begin{tabular}{|c|c|c|c|}
\hline \multirow{2}{*}{$\begin{array}{c}\text { Spore } \\
\text { concn }\left(\mathrm{ml}^{-1}\right)\end{array}$} & \multicolumn{3}{|c|}{ Percentage conversion to: } \\
\hline & Hycanthone (II) & Compound (III) & Compound (IV) \\
\hline $10^{8}$ & 28 & 18 & 15 \\
\hline $2 \times 10^{8}$ & 37 & 22 & 17 \\
\hline $3 \times 10^{8}$ & 34 & 18 & 18 \\
\hline $4 \times 10^{8}$ & 35 & 20 & 14 \\
\hline $10^{9}$ & 26 & 20 & 10 \\
\hline $10^{10}$ & 23 & 20 & 8 \\
\hline
\end{tabular}

Table 5. Stability of the Aspergillus spore enzymes for successive transformation of lucanthone

Number of
re-uses
1
2
3
4
5
6
7

$\overbrace{\text { Hycanthone (II) }}^{\text {Percentage conversion to: }} \begin{array}{ccc}\text { Compound (III) } & \text { Compound (IV) } \\ 37 & 6 & 17 \\ 36 & 10 & 15 \\ 38 & 8 & 10 \\ 33 & 6 & - \\ 26 & 12 & - \\ 32 & 11 & -\end{array}$

volume of phosphate buffer $\mathrm{pH}$ 5, and then re-used for the transformation of lucanthone (I). The results obtained are shown in Table 5. No significant loss in spore activity could be seen on re-using the spores for as much as seven times. However, the carboxylic acid analogue (IV) that was initially detected in the transformation medium could not be detected on successive re-use of the spores.

\section{DISCUSSION}

As compared to previously reported microbiological transformations of organic molecules (Charney \& Herzog, 1967; Vézina et al., 1968; Vézina \& Singh, 1975), our results indicate that the activity of moulds is not very versatile on lucanthone (I). All active lucanthone transformers were Aspergillus species and the 4-methyl group appeared to be the most susceptible position of the molecule since hycanthone (II) was obtained in all cases. In steroid, antibiotic or other organic matter biotransformations, non-germinating spores were more selective in their activity as compared to vegetative forms (Zedan, 1972; Vézina \& Singh, 1975). With lucanthone (I) as a substrate (Table 1), reactions which could be carried out by actively growing cultures or washed mycelia of active moulds were invariably performed by non-germinating spores.

Of the micro-organisms studied, the Aspergilus sp. no. 2 was among the most active cultures (Table 1). More than one reaction was effected by growing cultures as well as by washed mycelia and non-germinating spore suspensions of this strain. Lucanthone (I) was converted into a mixture of hycanthone (II), its aldehyde analogue (III) and the carboxylic acid derivative (IV). The most abundant member of the mixture was hycanthone (II) known to have schistosomicidal (Rosi et al., 1967) and anti-Trichinella spiralis (Gawish, 1974) activity.

In view of the foregoing results, it is likely that the non-germinating spores and mycelia of this Aspergillus strain oxidized lucanthone (I) in a series of reactions which eventually led to the formation of the carboxylic acid analogue (IV) via the sequence indicated in Fig. 1. The first step in the metabolism involves hydroxylation to the 4-hydroxymethyl derivative (hycanthone, II) followed by dehydrogenation of the resulting primary alcohol to give the aldehyde analogue (III); hydroxylation involves the participation of a 4-methylhydroxylase, whereas dehydrogenation involves the participation of a 4-hydroxymethyldehydrogenase. The aldehyde (III) was then slowly oxidized to the corresponding carboxylic acid (IV) which resisted further metabolism. 
Interconversions of ketone and hydroxy groups were among the first described transformations of organic molecules, particularly steroids, by micro-organisms (Charney \& Herzog, 1967). Thus, it was deemed desirable to determine whether the aldehyde (III) would undergo enzymic reduction into hycanthone (II) under the fermentation conditions. When the aldehyde (III) was incubated with either mycelium of spore suspensions of the Aspergillus sp. no. 2, no hycanthone (II) was formed; oxidation to the carboxylic acid (IV) likewise proceeded readily. This indicates that the enzymic dehydrogenation of hycanthone (II) to the aldehyde (III), is irreversible which is consistent with the findings of Sih et al. (1963) who reported that reduction of steroid aldehydes by micro-organisms are of rare occurrence.

Oxidation of lucanthone (I) into hycanthone (II) and other metabolites (III and IV) by growing cultures of Aspergillus could be by exo- or endo-enzymes, or both. From the results obtained, no transformation activity was detected in supernatants collected after removal of the mycelium from broth cultures by centrifugation. These findings show the participation of intrarather than extracellular enzymes in the transformation process.

Lag periods were observed in the transformation of steroids by the spores of fungi and actinomycetes (Vézina et al., 1968; Vézina \& Singh, 1975). This metabolic lag may be required for enzyme activation or may be attributed to cell wall permeability as no adaptive enzyme synthesis had occurred (Plourde \& Zedan, 1973). In this study, no lag period was observed in the course of transformation of lucanthone (I) by non-induced spore or mycelial suspensions, and the transformation products started to accumulate in the medium within $1 \mathrm{~h}$ of incubation with the substrate (Figs 2 and 3). The same course of transformation occurred in the presence of chloramphenicol or streptomycin indicating that no enzyme adaptation took place and that the enzymes participating in lucanthone (I) transformation by washed mycelium or nongerminating spores are constitutive in nature. The conversion activity of both forms was lost by autoclaving indicating the enzymic nature of their activity.

In view of the schistosomicidal activity of hycanthone (II) (Rosi et al., 1967), its over oxidation to the aldehyde analogue (III) and the carboxylic acid derivative (IV) is an undesirable reaction. Furthermore, since spore-mediated transformations could offer many advantages over classical fermentations by growing cell populations (Vézina et al., 1968; Vézina \& Singh, 1975), various factors that may affect the conversion of lucanthone (I) by the non-germinating spores of the Aspergillus sp. no. 2 were investigated. The results described here show that maximum transformation was obtained at a spore concentration of $2 \times 10^{8}$ to $4 \times 10^{8}$ spores $\mathrm{ml}^{-1}$ (Table 4) and no energy source was required. For hydroxylation of steroids, spores of Aspergillus ochraceus, Mucor griseo-cyanus and other fungi required exogenous energy sources of carbon (Vézina et al., 1963; Singh et al., 1967).

Although Vézina et al. (1968) and Plourde \& Zedan (1973) reported that steroid transformations by fungal spores are not strongly affected by variations in $\mathrm{pH}$ within fairly wide limits, optimum pH for lucanthone transformation by the spores of the Aspergillus sp. no. 2 was between 4 and 5 . Outside this range there was a gradual decrease in spore activity. Our results are consistent with the finding of Rosi et al. (1967) who reported that maximum transformation of this substrate with actively growing cultures of Aspergillus sclerotiorum was between 5.4 and 6 . A similar observation was also reported by Zedan \& El-Tayeb (1977) for the transformation of progesterone by the spores of Fusarium solani.

Substrate concentration has been reported to affect the transformation processes. Thus, it was reported that the nature or the yields of the transformation products, or both, may be altered by varying the concentration of the steroid substrate. For example, at a concentration more than $2 \mathrm{~g}$ $1^{-1}$, progesterone was almost completely converted into $11 \alpha$-hydroxyprogesterone by spores of Stachylidium theobroma; when the charge was less than $0.5 \mathrm{~g} \mathrm{l}^{-1}$, a certain amount of $6 \beta, 11 \alpha$ dihydroxyprogesterone was formed (Vézina \& Singh, 1975). Zedan \& El-Tayeb (1977) reported that increasing progesterone concentration increased the yield of androstadienedione and decreased the yield of 1-hydrotestololatone from progesterone by spores of $F$. solani. The results obtained in this study (Fig. 5) show that the overall activity of the spores and the yields of hycanthone (II) increased by increasing the substrate concentrations from 0.1 to $0.7 \mathrm{mg} \mathrm{ml}^{-1}$. At higher substrate concentrations activity was reduced. As reported by Rosi et al. (1967), this 
decrease in activity at high initial concentrations of lucanthone (I) could be attributed to its inherent fungicidal activity. The same authors reported that hycanthone (II) was much less potent in this respect and efficient conversion was achieved by gradual addition of lucanthone (I) to the fermentation medium at a rate that sublethal concentrations were maintained at all times.

Conversion of lucanthone (I) by spores of this micro-organism was not affected qualitatively when the transformation was carried out over a wide range of incubation temperature (Table 2) but maximum yields of hycanthone (II) were attained at $37^{\circ} \mathrm{C}$. In addition, spore enzymes participating in lucanthone (I) transformation appear to be heat-resistant (Table 3). Thus, activity was only slightly affected by heating spores to temperatures ranging between $\mathbf{4 0}$ and $100{ }^{\circ} \mathrm{C}$ for $1 \mathrm{~h}$ although complete loss of activity was observed on autoclaving at $121{ }^{\circ} \mathrm{C}$ for 10 min. Heat-resistance has been reported for enzymes of bacterial spores, e.g. the catalase from spores of Bacillus terminalis (Lawrence \& Halvorson, 1954) and the soluble reduced nicotinamide adenine dinucleotide oxidase from spores of Clostridium botulinum (Green \& Sadoff, 1965; Simmons \& Costilow, 1962).

The enzyme systems participating in the hydroxylation of lucanthone (I) into hycanthone (II) and subsequent oxidation to the corresponding aldehyde analogue (III) appear to be more stable than the enzyme system involved in the final oxidation of the aldehyde (III) to the carboxylic acid (IV). Thus, although no significant decrease in the yields of hycanthone (II) and the aldehyde (III) was observed on successive re-use of the spores, the carboxylic acid (IV) (an undesirable impurity) was not formed (Table 5). The appearance of the aldehyde (III) with hycanthone (II) at all times under various experimental conditions represents no real problem. The incorporation of $\mathrm{NaBH}_{2}$ could convert this troublesome product to the desired hycanthone (II) (Rosi et al., 1967).

\section{REFERENCES}

BLAIR, D. M. (1958). Human tolerance of lucanthone. Bulletin of World Health Organization 18, 989.

Charney, W. \& Herzog, H. L. (1967). Microbial Transformations of Steroids - A handbook. New York \& London: Academic Press.

GAWISH, N. (1974). Hycanthone (etrenol) in treatment of experimental trichinosis. Al-Azhar Medical Journal 3, 4 .

Green, J. H. \& Sadoff, H. L. (1965). Comparison of soluble reduced nicotinamide adenine dinucleotide oxidases from cells and spores of Clostridium botulinum. Journal of Bacteriology 89, 14991505 .

KIKUTH, W. \& GöNNERT, R. (1948). Experimental studies on the therapy of schistosomiasis. Annals of Tropical Medicine and Parasitology 42, 256-267.

Lawrence, N. L. \& Halvorson, H. O. (1954). Studies on the spores of bacteria. IV. A heat resistant catalase from spores of Bacillus terminalis. Journal of Bacteriology 68, 334-337.

Plourde, R. \& Zedan, H. H. (1973). Distribution of steroid 1-dehydrogenation and side-chain degradation enzymes in the spores of Fusarium solani: causes of metabolic lag and carbohydrate independence. Applied Microbiology 25, 650-658.

Rosi, D., Peruzzotti, G., Dennis, E. W., Berberian, D. A., Freele, H. \& Archer, S. (1965). A new active metabolite of Miracil.D. Nature, London 208, 1005-1006.

Rosi, D., Peruzzotti, G., Dennis, E. W., Berberian, D. A., Freele, H. \& ARCHER, S. (1967). Hycanthone, a new active metabolite of lucanthone. Journal of Medicinal Chemistry 10, 867-876.

Sih, C. J., Kupchan, S. M., Katsui, N. \& El-Tayeb, O. M. (1963). Microbiological transformations. III.
Reduction of the steroid C-19 aldehyde group. Journal of Organic Chemistry 28, 854-855.

Simmons, R. J. \& Costilow, R. N. (1962). Enzymes of glucose and pyruvate catabolism in cells, spores and germinated spores of Clostridium botulinum. Journal of Bacteriology 84, 1274-1281.

Singh, K., Sehgal, S. N. \& VéziNA, C. (1967). Transformation of steroids by Mucor griseo-cyanus. Canadian Journal of Microbiology 13, 1271-1281.

Stahl, E. (1969). Thin-Layer Chromatography, A Handbook, 2nd edn, pp. 135-138. Berlin: SpringerVerlag.

VÉzINA, C. \& SINGH, K. (1975). Transformation of organic compounds by fungal spores. In The Filamentous Fungi, vol. I., Industrial Mycology, pp. 158192. Edited by J. E. Smith \& D. R. Berry. London: Edward Arnold.

Vézina, C., Sehgal, S. N. \& Singh, K. (1963). Transformation of steroids by spores of microorganisms. I. Hydroxylation of progesterone by conidia of Aspergillus ochraceus. Applied Microbiology 11, 50-57.

Vézina, C., Sehgal, S. N. \& Singh, K. (1968). Transformation of organic compounds by fungal spores. Advances in Applied Microbiology 10, 221268.

ZEDAN, H. H. (1972). A contribution to the study of 1dehydrogenation and side-chain degradation of steroids by microbial spores. Ph.D. thesis, University of Montreal, Montreal, Canada.

Zedan, H. H. \& El-TaYeb, O. M. (1977). Microbiological transformations of steroids. IV. Factors affecting the transformation of progesterone by nongerminating spores of Fusarium solani. Planta medica 31, 163-172. 